\title{
Case Report: Deep Venous Thrombosis and Pulmonary Thromboembolism in a Physically Nonprepared Trekker in the Himalayas: An Autopsy Report
}

\author{
Senthil Kumar $^{1}$ (D), Y. S. Bansal ${ }^{*}$, Dilip Vaishnav¹ , Lakshmi Narayanan¹
}

1. Department of Forensic Medicine, Post Graduate Institute of Medical Education \& Research, Chandigarh, India.

\begin{tabular}{|c|c|}
\hline $\begin{array}{l}\text { Use your device to scan } \\
\text { and read the article online }\end{array}$ & Citation Kumar S, Bansal YS, Vaishnav D, Narayanan L. Deep Venous Thrombosis and Pulmonary Thromboembolism \\
\hline 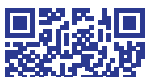 & $\begin{array}{l}\text { in a Physically Nonprepared Trekker in the Himalayas: An Autopsy Repor. International Journal of Medical Toxicology and } \\
\text { Forensic Medicine. 2021; 11(4):34555. https://doi.org/10.32598/ijmtfm.v11i4.34555 }\end{array}$ \\
\hline mosys & doijhttps://doi.org/10.32598/ijmtfm.v11i4.34555 \\
\hline
\end{tabular}

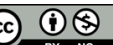

Article info:

Received: 13 Apr 2021

First Revision: 25 Apr 2021

Accepted: 06 May 2021

Published: 21 Dec 2021

\section{Keywords:}

High altitude, Deep vein thrombosis, Pulmonary thromboembolism, Hypoxia, Virchow's triad

\section{A B S T R A C T}

Deep Venous Thrombosis (DVT) and Subsequent Pulmonary Thromboembolism (PTE) in high altitude climbers is a well-known concept. The acclimatization process at high altitude is itself a thrombogenic event. Accordingly, when a physically nonprepared individual with preexisting thrombogenic risk factors attempts trekking at high altitude, they may end up with fatal thromboembolic events. Here, we report a case of a low-lander with multiple thrombogenic risk factors who developed DVT and PTE when he went for a trekking trip in the Himalayas. The risk factors, autopsy findings, and possible mechanism of developing fatal pulmonary embolism, in this case, are discussed here.

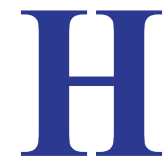

\section{Introduction}

igh-altitude illness is a well-known concept; the various spectrum of this illness is acute mountain sickness (AMS), high-altitude pulmonary edema (HAPE), and high-altitude cerebral edema (HACE). High-altitude pulmonary embolism is a rare entity of this illness. The high-altitude may pose many challenges and can lead to potentially thrombogenic events for a trekker, especially in a lowlander who is not acclimatized to such an environment. In such a scenario, when a non-prepared trekker with multiple pre-existing thrombogenic risk factors attempts highaltitude trekking, it may lead to fatal pulmonary thromboembolism. We discuss one such case in this report.

* Corresponding Author:

Y. S. Bansal, MD.

Address: Department of Forensic Medicine, Post Graduate Institute of Medical Education \& Research, Chandigarh, India Tel: +98 (911) 722755206

E-mail: yogendrabansal@hotmail.com 


\section{Case Presentation}

33-year-old morbidly obese (140 kg) male healthcare professional went on a trekking trip with his female friend to Churdhar, a well-known trekking site of the Sivalik range of the outer Himalayas, the state of Himachal Pradesh, India. He presented no symptoms while starting the trip; however, he was diagnosed with Obstructive Sleep Apnea (OSA) and pre-diabetic. He was a smoker (5 pack-years) and heavy drinker (15-20 drinks per week) with the habit of binge drinking on weekends. He was observed with laboured breathing while using stairs by his friends on several occasions; however, he was not a known asthma case. He had varicose veins in both legs and suffered from pedal edema on numerous occasions. Apart from the above-mentioned thrombogenic risk factors, there was no past history of thrombophilia. He was also under psychological stress because of not finding a suitable job, matching his academic achievement.

On the first day of the trip, he and his friend started at $6.30 \mathrm{AM}$ by a taxi from Chandigarh $(321 \mathrm{~m}$ above sea level) and traveled $135 \mathrm{~km}$ to reach Nohradhar, the starting point of the trek (2171 $\mathrm{m}$ above sea level). They arrived at $10.15 \mathrm{AM}$, and throughout the journey, he was sleeping in the car's back seat. During this 4-hour journey, he had ascended $1850 \mathrm{~m}$. The region's maximum temperature was between $26-280 \mathrm{C}$, and the minimum temperature was between $10-120 \mathrm{C}$ during his stay. After having their breakfast, they started trekking at 11.30 AM. They reached the first campsite, 'Pahli,' $4 \mathrm{~km}$ away from Nohradhar, in the evening at about 7 PM. During this trekking, he complained of difficulty in breathing and altered voice. They spent their night at the campsite, and the deceased felt very tired during that night.

On the second day, they again started trekking at 10 AM. They reached 'Jamnala,' the second campsite, at 2 PM., i.e., located two km away from the first campsite and then to the third campsite, 'Teesri' (3048 $\mathrm{m}$ above sea level, $5 \mathrm{~km}$ away from the second campsite), at 6:20 PM. Thus, on the second day, they trekked $7 \mathrm{~km}$ by ascending from $2171 \mathrm{~m}$ to $3048 \mathrm{~m}$, i.e., $877 \mathrm{~m}$ further up in approximately 8 hours. That evening he complained about having leg pain.

On the third day morning, at about 9 AM, he woke up with a complaint of leg pain and severe headache. Due to this, he decided to rest at the campsite and refused further trekking. He insisted his friend continue trekking with the guide. Then, he spent the whole day alone, taking a rest by lying on the bed. When his friend returned to the campsite at $5 \mathrm{PM}$, he complained of severe leg pain, shortness of breath, and headache. As he felt too sick, he asked her to arrange some medication; however, she could not get it, as the campsite was remote and devoid of medical facilities. After having coffee, he went to bed at around 9 PM. After about 5 hours, at approximately $2.30 \mathrm{AM}$, he encountered severe breathlessness and frothing from mouth and nose, and subsequently, he went into an unconscious state.

Immediately his friend called the emergency helpline; simultaneously, nearby people tried Cardio-Pulmonary

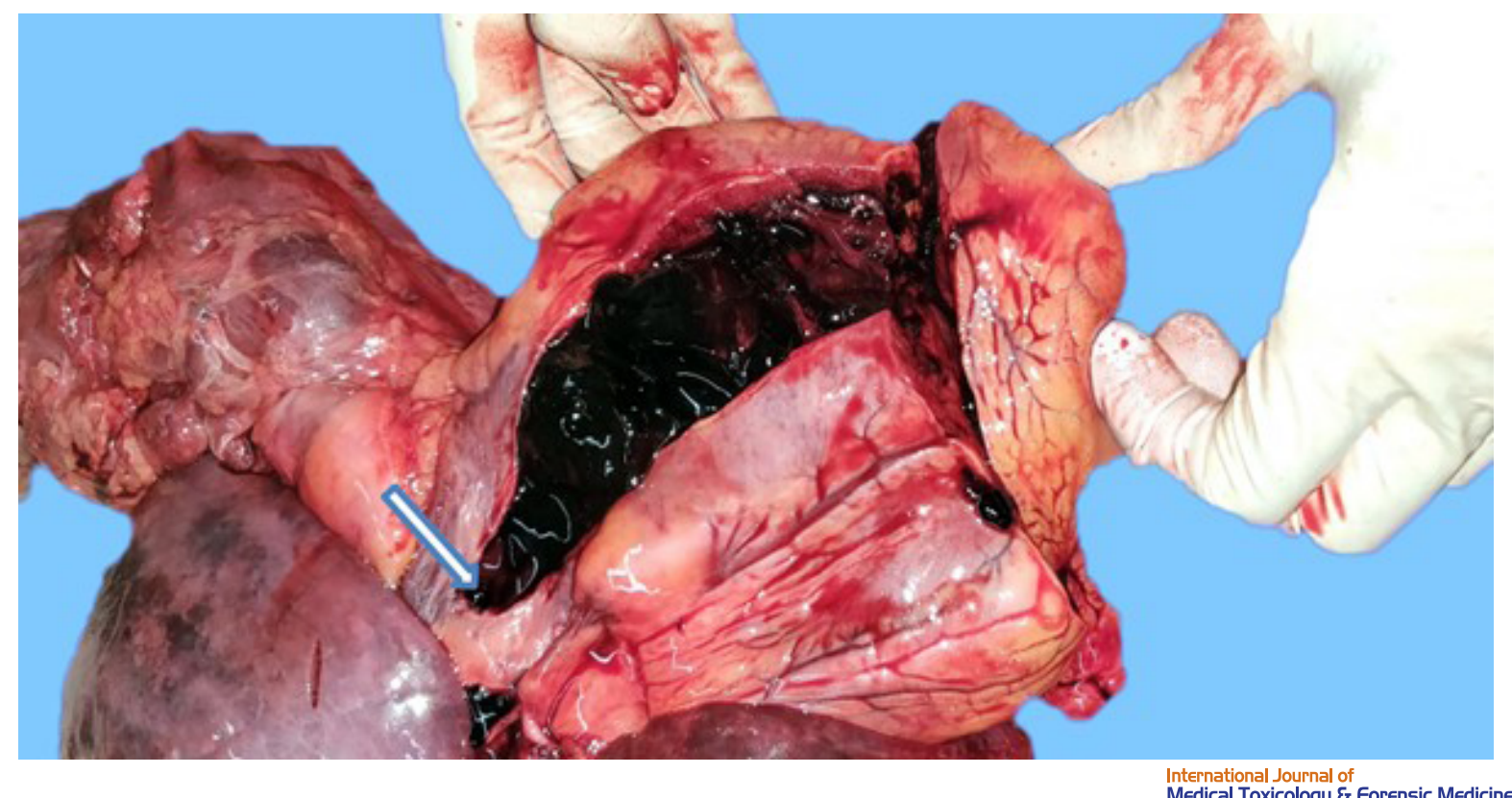

Figure 1. Dark red clots in the heart's right chamber extending into the pulmonary artery (arrow) 


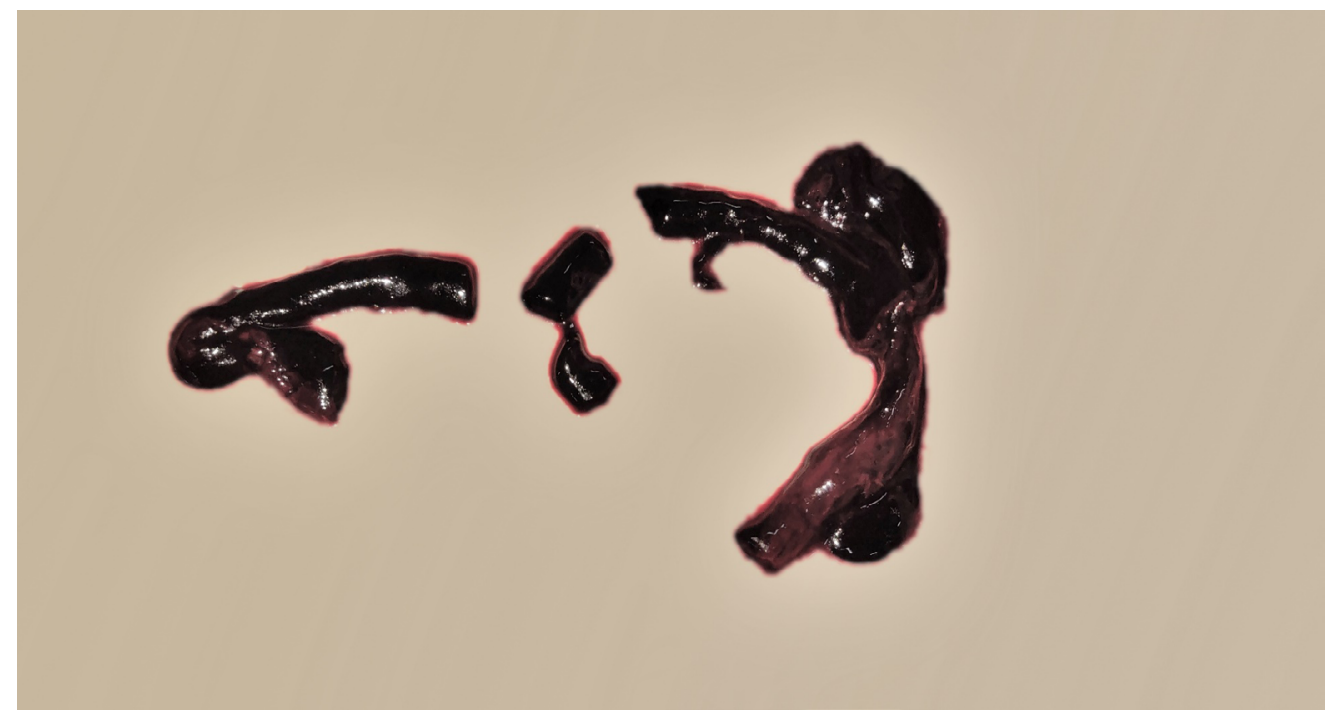

Figure 2. Dark red thrombus with tan areas in-between, from deep veins of both legs

Resuscitation (CPR). Due to the difficult terrain, the police and the rescue team could reach the campsite only in the morning at around $9 \mathrm{AM}$. He was then declared dead by a pharmacist, one of the rescue team members. The deceased was brought down on a stretcher with difficulty and was brought for postmortem examination. A forensic autopsy was conducted considering the medicolegal nature of the case.

\section{Autopsy findings}

The deceased was an obese male of length $189 \mathrm{~cm}$ with abundant belly fat on external examination. His weight was $140 \mathrm{~kg}$ with a Body Mass Index (BMI) of $39.2 \mathrm{~kg} /$ $\mathrm{m}^{2}$ (obese class II). He was cyanosed, and blood-tinged fluid was noted in both nostrils. Bilateral conjunctival congestion and dilated superficial leg veins of both legs were found. The frontal region of the scalp showed one minor reddish contusion.

On internal examination, there was no skull fracture or any intracranial hemorrhage. All the visceral organs were congested. The heart was enlarged, the right atrium and ventricle were dilated and filled with dark red clots (Figure 1). The clot extended into the main pulmonary trunk and further into its branches. Clots were dark red with pale tan areas in between and adherent to the vessel wall. The root of the aorta presented atheromatous plaques. The major coronary arteries indicated intimal thickening and atherosclerotic changes. Both lungs were edematous and hemorrhagic at multiple places. Pulmonary artery branches revealed dark red thrombi on the cut section at numerous places, predominantly on the lower lobe. The liver was found enlarged and showed fatty changes. The popliteal vein on both legs manifested a thrombus on the dissection of the legs in the popliteal fossa (Figure 2). Urine was screened for alcohol and drugs of abuse using 'rapid urine DOA/Alcohol panel test dip card/cassettes'; it tested positive for fentanyl. Urine and blood samples were sent to the state forensic science laboratory for further confirmatory analysis for fentanyl. The result came negative for alcohol, common poisons, fentanyl, and other drugs.

On microscopic examination, sections from the pulmonary artery suggested that the lumen was almost occluded by thrombus with abundant fibrin and entrapped RBCs, platelets, and white cells (Figure 3). Lungs indicated severe pulmonary edema with compensatory emphysematous changes at places with damage to the alveolar linings (Figure 4). The liver showed extensive fatty changes. Spleen and kidney revealed no significant morphological change. The cause of death was concluded as Deep Vein Thrombosis (DVT) resulted in PTE in a high altitude trekker.

\section{Discussion}

Trekking is a recreational activity usually practiced by young people of both genders for pleasure and a trophy of their athletic performances. However, if it is not performed with proper guidance or in a healthy condition, trekking at a high altitude may lead to fatal outcomes ranging from hospitalization to death $[1,2]$. Acute altitude illness is a well-known concept. The various spectrum of this illness is Acute Mountain Sickness (AMS), High Altitude Cerebral Edema (HACE), High Altitude 


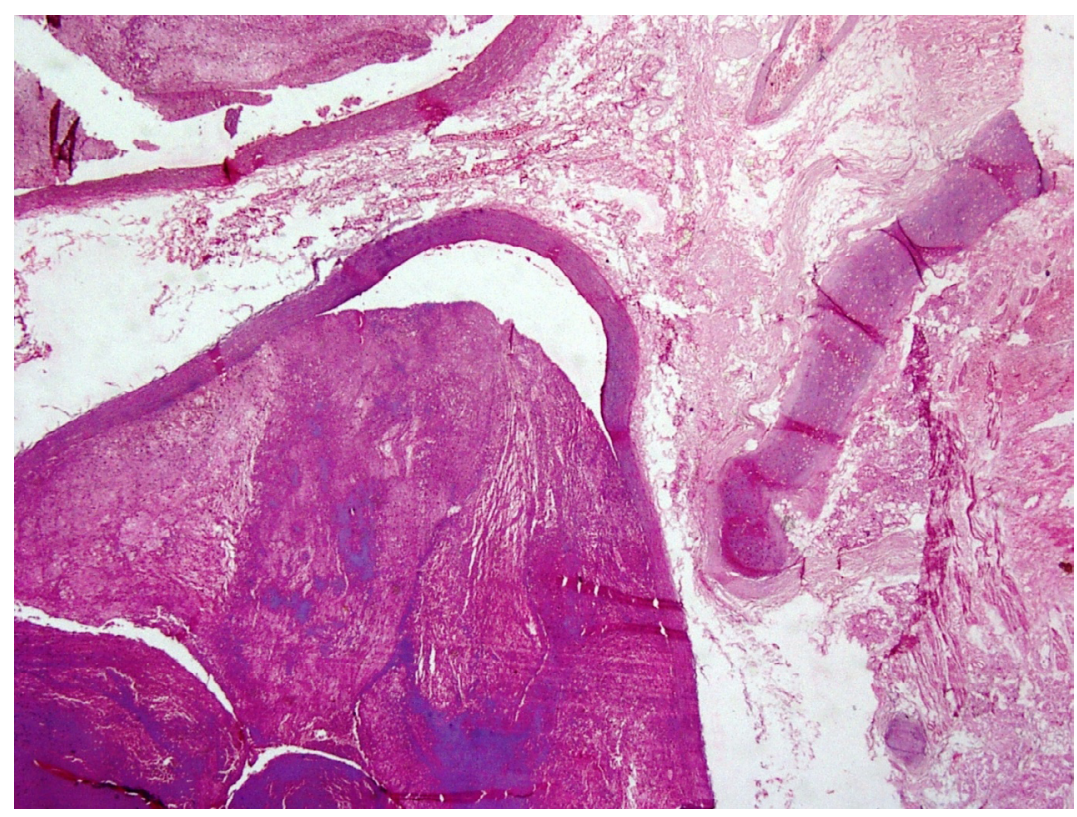

International Journal of

Forensic Medicine Figure 3. Sections from the pulmonary artery showed that the lumen was almost occluded by thrombus with abundant fibrin and entrapped RBCs, platelets, and white cells

Pulmonary Edema (HAPE), and the rare presentation of high-altitude pulmonary thromboembolism [3].

Generally, PTE is a complication of Deep Vein Thrombosis (DVT) of the lower limbs. The risk factor for DVT development has long been understood and explained by Virchow's triad, which includes a reduction in blood flow (circulatory stasis), changes in blood viscosity (hypercoagulability), and vessel wall damage. Major surgery, trauma, pregnancy, use of contraceptive pills, infection, sleep apnea, immobility or enforced inactiv- ity, atrial fibrillation, left ventricular dysfunction, varicose vein, thrombophlebitis, and indwelling catheters or valve are some of the risk factors to enumerate $[4,5]$.

High altitude is also among the risk factors causing venous thrombosis, which may eventually lead to fatal PTE $[6,7]$. The acclimatization process brings a thrombogenic response, like hemoconcentration. Hypoxia encountered at high altitude leads to a marked increase in red blood cells and hemoglobin and increased blood volume by $20 \%-30 \%$, leading to hemoconcentration and

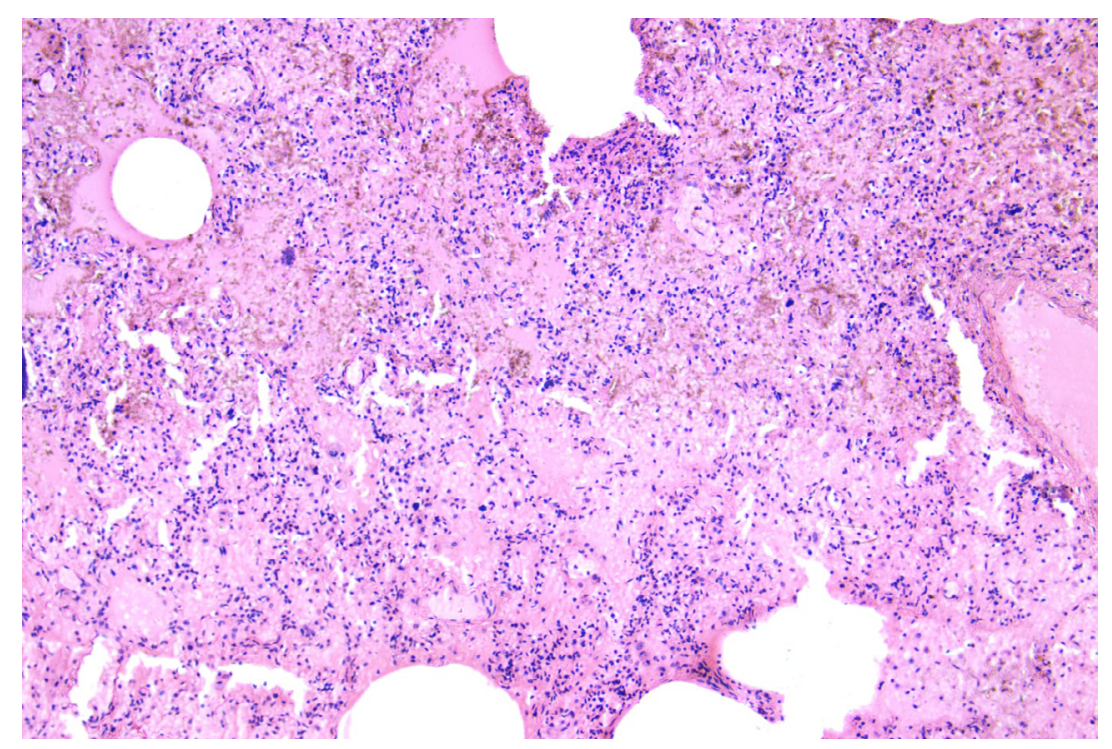

Figure 4. Lungs showed severe pulmonary edema with damage to the alveolar linings 
increased blood viscosity [8]. The trekkers may also be exposed to other thrombogenic risk factors such as dehydration, muscle injuries, fracture, vascular trauma, and immobilization before or during trekking due to longdistance travel $[8,9]$.

In our case, the planned trip was a very exhaustive journey and was not advisable when considering the deceased's health condition. The deceased already had the risk factors, such as smoking, psychological stress, compromised lower leg veins, central obesity, and OSA. With these preexisting risk factors, the deceased was immobile during his four-hour car travel, which would have initiated DVT development at the onset of the trip itself. Furthermore, the thrombogenic acclimatization process at the high altitude would have led to DVT progression into PTE. The hyperactivity during trekking followed by immobility for the whole third day could also have contributed to PTE development. The literature also highlighted that psychosocial stress, like job strain, causes a chronic low-grade hypercoagulable state $[1,10]$. The deceased was also constantly having job pressure because of not finding a suitable job profile and extreme unfruitful workload in the current job. More careful attention to the risk factors, symptoms, earlier suspicion of DVT, and timely intervention in the form of an urgent evacuation to a medical facility could have saved his life.

The reddish contusion over the scalp's frontal region is probably a perimortem injury that occurred during resuscitation or transport of the deceased. From a forensic perspective, considering the absence of struggle marks on the body, negative toxicology report, and the finding of pulmonary thromboembolism on autopsy and histopathology examination, we ruled out the possibility of any homicidal angle in this case.

\section{Conclusion}

The authors observed that individuals with preexisting lifestyle disorders are at increased risk of developing DVT and fatal PTE when trekking at a high altitude. This case report urges the importance of undergoing health check-ups and screening risk factors before going for high-altitude trekking, especially in the lowlander. We recommend the Government of India ensure adequately equipped trekking sites with medical facilities and a proper evacuation plan in an emergency. The timely diagnosis and treatment may avoid the loss of lives.

\section{Ethical Considerations}

\section{Compliance with ethical guidelines}

There were no ethical considerations to be considered in this research.

\section{Funding}

This research did not receive any grant from funding agencies in the public, commercial, or non-profit sectors.

\section{Author's contributions}

Conceptualization and Supervision: Senthil Kumar R and Yogender Singh Bansal; Methodology: Senthil Kumar R, Yogender Singh Bansal and Dilip Vaishnav; Investigation, Writing - original draft, and Writing - review \& editing: All authors.

\section{Conflict of interest}

The authors declared no conflict of interest.

\section{Acknowledgements}

We acknowledge Mrs. Sujata, our Forensic histopathology laboratory staff, for her work in this case. The authors thank the deceased's friends and colleagues for their valuable information regarding their medical history and the events during the trekking trip.

\section{References}

[1] Hull CM, Rajendran D, Fernandez Barnes A. Deep vein thrombosis and pulmonary embolism in a mountain guide: Awareness, diagnostic challenges, and management considerations at altitude. Wilderness Environ Med. 2016; 27(1):100-6. [DOI:10.1016/j.wem.2015.10.010] [PMID]

[2] Pandey P, Lohani B, Murphy H. Pulmonary embolism masquerading as high altitude pulmonary edema at high altitude. High Alt Med Biol. 2016; 17(4):353-8. [DOI:10.1089/ ham.2016.0008] [PMID] [PMCID]

[3] Obrowski M, Obrowski S. Deadly High Altitude Pulmonary Disorders: Acute Mountain Sickness (AMS); High Altitude Pulmonary Edema (HAPE) and High Altitude Cerebral Edema (HACE): A Clinical Review. Int J Pul Res Sci. 2016; 1(1):555553. [DOI:10.19080/IJOPRS.2016.01.555553]

[4] Heit JA, Silverstein MD, Mohr DN, Petterson TM, O'Fallon WM, Melton LJ 3rd. Risk factors for deep vein thrombosis and pulmonary embolism: A population-based case-control 
study. Arch Intern Med. 2000; 160(6):809-15. [DOI:10.1001/ archinte.160.6.809] [PMID]

[5] Latshang TD, Bloch KE, Lynm C, Livingston EH. JAMA patient page. Traveling to high altitude when you have sleep apnea. JAMA. 2012; 308(22):2418. [DOI:10.1001/ jama.2012.4097] [PMID]

[6] Srivastava S. Travelling to high altitudes could be thrombogenetic!. Arch Pulmonol Respir Care. 2015; 1(1):023-7. [DOI:10.17352/aprc.000006]

[7] Kumar S. High altitude induced deep venous thrombosis: A study of 28 cases. Indian J Surg. 2006; 68:84-8. http:/ / hdl. handle.net/1807/6394

[8] Segler CP. Prophylaxis of climbers for prevention of embolic accidents. Med Hypotheses. 2001; 57(4):472-5. [DOI:10.1054/ mehy.2001.1367] [PMID]

[9] Gupta N, Ashraf MZ. Exposure to high altitude: A risk factor for venous thromboembolism? Semin Thromb Hemost. 2012; 38(2):156-63. [DOI:10.1055/s-0032-1301413] [PMID]

[10] Austin AW, Wissmann T, von Kanel R. Stress and hemostasis: An Update. Semin Thromb Hemost. 2013; 39(8):902-12. [DOI:10.1055/s-0033-1357487] [PMID] 